\title{
Envisioning Probe Kit: Creativity and Storytelling to Capture the Inner Thoughts of People
}

\author{
Patrizia Andronico ${ }^{1}$, Patrizia Marti $^{2}$, and Maurizio Martinelli ${ }^{1}$ \\ ${ }^{1}$ Istituto di Informatica e Telematica del CNR \\ Via G. Moruzzi, 1, Pisa, Italy \\ \{patrizia.andronico, maurizio.martinelli\}ait.cnr.it \\ ${ }^{2}$ Dipartimento di Science della Comunicazione, Università di Siena \\ Via Roma 56, 53100 Siena, Italy \\ marti@unisi.it
}

\begin{abstract}
During the last few years the interest in Information and Communications Technologies (ICT) fields has spread towards wireless and mobile devices which can support activities in everyday life. Designing for play, learning and awareness is becoming more and more a factual aspects of research willing to meet users' needs. In such a broaden range of possible applications for the new ubiquitous and pervasive technologies, classical HCI methods for revealing efficiency and effectiveness of an innovative product are no more adequate. Taking into consideration human experience during the interaction with ICT devices needs a more creative and multidisciplinary design approach. This work was developed within a European project called MobileMAN ${ }^{1}$ whose aim was to develop a self-organizing and infrastructureless network with the potentiality of the well-known MANET (Mobile Ad hoc NETwork) paradigm. Our goal in the MobileMAN project was to investigate with potential end users, the possible applications useful for everyday activities that could work with this emerging technology. We then tried to adopt a more creative and multidisciplinary approach, inspired by the "Probe Kit" developed at the Royal College of London.
\end{abstract}

Keywords: ubiquitous computing, probe kit, creativity, storytelling, UCD, Cultural Psychology.

\section{Mobile Ad Hoc NETworks}

A MANET is a wireless network without any type of infrastructure, autonomous and suitable enough for creating a communication link between people who are sharing an activity or are meeting up casually. This kind of network is rather spontaneous and generally temporary in time. Users can collaborate each others until they stay in the same place where the network is been formed; when they go away from this point, in

${ }^{1}$ MobileMAN (http://cnd.iit.cnr.it/mobileMAN), has been studied and developed within a European research activity funded by the European Community in the "Information Society Technologies (IST)" program as a Future Emerging Technology project. The project started in October 2002 and terminated in December 2005. 
fact, connections are not still available and people will no longer communicate. A MANET is quite useful in a citizen network environment, just because any single node can act as router switch, bridge or server, being free of infrastructure constraints. Such a characteristic should decrease communication expenses while increasing societal communication abilities. Concepts like mobility and ubiquitous computing are becoming essential in the new nomadic societies: information and services need to be accessible from anywhere and in anytime.

Disaster recovery or military situations are the most common applications developed through mobile wireless ad hoc networks. Only recently the interest is moving towards civilian applications, such as data sharing during a meeting, on-the-road safety, aged assistance, and even monitoring of savage animals to study habits and movements [1]. MobileMAN project has reserved a special attention on the implication of ICT to improve the quality of life and social cohesion, as envisioned in [2].

\section{Theoretical Framework and Experimental Set Up}

For the definition of the experimental phase, we took into consideration the theoretical framework known as Cultural Psychology, considering two of the most important contributors of the discipline: Lev Vygotsky and Jerome Bruner. While the Vygotsky's work is mainly concentrated on the creativity activities inside any person, Bruner has concentrated his studies on the importance of storytelling in the creation of the self. Creativity for Vygotsky is in the society itself: each person learns anything and internalizes it from the social context, from which they can then produce some new creative idea [3]. Story creation (fictional stories) and storytelling in general, seem to help children in building around their own personal vision of the world [4].

Usually considered in pedagogical and educational areas, recently several researchers recovered and recognized Vygotsky and Bruner studies as important resources for the design of new methodological approach in the modern Information and Communication Society. As pointed out in [5], "Social, historical and cultural dimensions of cognition are receiving increasing attention, and their relevance in developing collaboration technologies is widely recognized".

For the experiment we designed and set up the "Envisioning Probe Kit". We propose the kit as a set of activities to be carried out by a group of 18 persons, constituted by student of the Engineering Faculty of the University of Pisa. We chose this particular group of student because they have already participated to other more technical experiment in the MobileMAN project and for this reason they had a strong expertise in Ad hoc Networks issues. This common ground could be useful for a better comprehension of the purpose of the experiment, but not at all necessary to deal with the Probe kit.

The aim of the probe kit was to involve users in the design process from the beginning, collecting information about their private life and providing designers with a deeper knowledge of people daily habits and activities. Gathering data from people in such a way it is quite difficult to be analyzed due to the ambiguity they took in that reflect ambiguities in real life, in speech, in images, and in most of our activities. In the context of data collected with the probe kit, ambiguity is seen as an opportunity for designers to be inspired mainly for technological applications not related to work 
context. In our time most of the new technologies affect everyday lives in situation like play, learning or awareness, and people more and more are asking for applications for fun or their spare times.

\section{The Envisioning Probe Kit Activities}

The Envisioning Probe was formed by activities from the original probe (such as taking picture, making a collage, commenting pre-stamped postcards), and activities we add on purpose for this particular occasion. Specifically we create a group blog where any participant could write personal stories, or inventing some, or only commenting stories written by the others. We opted for a blog because in the recent years is becoming a very important tool, not only as a personal diary, as it was in the original intention, but also as collaborative web pages, so easy to update. In this way we wanted to explore the collaboration between the single participants of the experiment as well as trying to capture the inner thought of each ones, who could be free to write whatever they wanted without being recognized because of a nickname chose in advance. We add also an activity, called "e-card", in which participants should comment and forward to others cards we previously sent them by email. With the e-cards we wanted to compare the use of electronic mail for sending card in relation with the traditional postcard.

At the first meeting with the group, we illustrated the activities of the kit and gave them the folder with all the tools they needed for the experiment, as shown in table 1.

Table 1. Activities of the Envisioning Probe Kit

\begin{tabular}{|c|c|c|c|}
\hline Activities & Action to be performed & Aim & Results \\
\hline $\begin{array}{l}\text { Traditional } \\
\text { postcard }\end{array}$ & $\begin{array}{l}\text { Each kit had a set of } 5 \text { postcards pre- } \\
\text { stamped and with a fixed address, } \\
\text { prepared with a photo and a comment. } \\
\text { The participants had to comment the } \\
\text { postcard, if they wanted to, and pass to } \\
\text { another person that should do the } \\
\text { same. The last person had to post the } \\
\text { postcard by a fixed date. }\end{array}$ & $\begin{array}{l}\text { Investigate the collaboration } \\
\text { between people as well as the } \\
\text { multi-hop of the passing } \\
\text { postcards. Explore the } \\
\text { comment participants left on } \\
\text { the card. }\end{array}$ & $\begin{array}{l}48 \% \text { of the postcards returned } \\
\text { to us with some comments. } \\
47 \% \text { of the comments were } \\
\text { made by a single person, while } \\
53 \% \text { were the multi-hop } \\
\text { activity with more than one } \\
\text { comment. }\end{array}$ \\
\hline Photos & $\begin{array}{l}\text { Each kit had a list of } 20 \text { items } \\
\text { participants should explore by taking a } \\
\text { picture and sending to us by email. }\end{array}$ & $\begin{array}{l}\text { Personal reflection on } \\
\text { everyday topics explored } \\
\text { with a visual mode of } \\
\text { communication. }\end{array}$ & $\begin{array}{l}13 \text { persons out of } 18 \text { sent us the } \\
\text { photos required, often not } \\
\text { completing the entire set. }\end{array}$ \\
\hline Collage & $\begin{array}{l}\text { Each kit had just a theme that any } \\
\text { participant could explore with any } \\
\text { possible technique used in a collage. }\end{array}$ & $\begin{array}{l}\text { Personal reflection on the } \\
\text { theme proposed and research } \\
\text { of the images, text, and } \\
\text { whatever they needed to } \\
\text { complete the task. }\end{array}$ & $\begin{array}{l}\text { Only } 4 \text { person out of } 18 \\
\text { complete the collage. }\end{array}$ \\
\hline Blog & $\begin{array}{l}\text { Personal and collaborative blog lasted } \\
\text { for two weeks. }\end{array}$ & $\begin{array}{l}\text { Personal reflection. } \\
\text { Investigate on the ability of } \\
\text { inventing stories, or } \\
\text { interacting with the other } \\
\text { posts, using one of the most } \\
\text { innovative tools for } \\
\text { communicating online. }\end{array}$ & $\begin{array}{l}13 \text { person out of } 18 \text { write on the } \\
\text { blog. }\end{array}$ \\
\hline e-cards & $\begin{array}{l}5 \text { e-cards were sent to each participant } \\
\text { that should comment and send to } \\
\text { other, similar to the activity with the } \\
\text { traditional postcard. }\end{array}$ & $\begin{array}{l}\text { Compare this activity with } \\
\text { the email, with the traditional } \\
\text { sending of postcards. }\end{array}$ & $\begin{array}{l}\text { None of the e-cards were } \\
\text { returned. }\end{array}$ \\
\hline
\end{tabular}


Each activity had a different time to be performed, and the entire experiment lasted for about two months. All the participants had a different implication in each activity, maybe due to their personal ability in completing the tasks. In any case during the experiment the atmosphere within the group was quite enthusiastic and collaborative.

\section{Conclusion and Future Works}

The amount of data we collected in such a way took with them a lot of ambiguity related to the personal and inner thoughts of the participants. Ambiguity arises from Conceptual Art movement of the 60s where the attention was mainly on ideas rather than on form. While technologies are increasingly adopted outside the work place, ambiguity seems to reach a great interest for design in HCI fields.

Analyzing such a set of data, and particularly, crossing the possible interpretations, it was a big work for designers, not yet completed. Firstly we started redistributing some of the data returned from the entire kit according to four maps related to: public and private spaces, activities in everyday lives, relationships, technological and not technological tools. The maps helped us in reflecting better on the possible scenario that could match the desiderata we found in the responses of the experiment, and the requirements of the MobileMAN technology.

For the future we would like to create some mock-up from the scenarios and test them again with potential end users.

\section{References}

1. Pelusi, L., Passarella, A., Conti, M.: Beyond MANETs: dissertation on Opportunistic Networking, Tech. Report 2006/01, Computer Networks Department, IIT - CNR, Maggio (2006), http://bruno1.iit.cnr.it/ bruno/techreport.html

2. Ducatel, K., Bogdanowicz, M., Scapolo, F., Leijten, J., Burgelman, J.-C.: Scenario for Ambient Intelligence in 2010. European Commission Community Research Finall Report, Seville, (2001), http://www.cordis.lu/ist/istag.htm

3. Vygotsky, L.S.: Mind in society: The development of higher psychological processes. In: Cole, M., John-Steiner, V., Scribner, S., Souberman, E. (eds.) Harvard University Press, Cambridge (1978)

4. Bruner, J.S.: The culture of education. Harvard University Press, Cambridge (1996)

5. Tuomi, I.: Vygotsky in a TeamRoom: an exploratory study on collective conceptformation in electronic environments, System Sciences (1998) 